\title{
FROM SEEDLING TO SAPLING: TREE SPECIES RESPONSES TO SPATIAL AND TEMPORAL UNDERSTORY LIGHT HETEROGENEITY IN DISTURBED TROPICAL MONTANE FORESTS
}

\author{
Guadalupe Méndez-Dewar ${ }^{1}$, Mario González-Espinosa ${ }^{2}$ and Miguel Equihua ${ }^{1,3}$ \\ ${ }^{1}$ Red de Ambiente y Sustentabilidad, Instituto de Ecología, A. C. Xalapa, Veracruz, México \\ ${ }^{2}$ Departamento de Conservación de la Biodiversidad, El Colegio de la Frontera Sur. \\ San Cristóbal de Las Casas, Chiapas, México \\ 3Corresponding autor: equihuam@gmail.com
}

\begin{abstract}
Difficulties in measuring small-scale light heterogeneity in forest understories is reflected in the classification of species, conventionally based on their responses to gaps or shade, rarely present in uniform conditions in space and time. Spatial and temporal heterogeneity expressed as a contrast between direct vertical light and light coming from the surroundings allows for a better assessment of the understory light environment and thus of the effect of its variation on species performance. Using repeated measures, we evaluated the effect of vertical light, contrast, and distance to the gap center on the performance of transplanted seedlings of Alnus acuminata, Cornus excelsa, Liquidambar styraciflua, Quercus laurina and Persea americana. Highlands of Chiapas between 1999 and 2005 in eight plots of pine-oak forest, each one with a small gap in the middle. Illumination was evaluated with hemispherical photographs at the beginning and the end of the study. We measured stem slenderness and survival after one, two, four, and six years following transplantation. Distance had an effect on survival of Alnus and Liquidambar. Vertical light only had an effect on Liquidambar slenderness. Contrast explained slenderness of Liquidambar, Cornus and Quercus, and survival of Liquidambar, Quercus and Persea conditional on plant age. Initial light contrast predicted the final condition well, which vertical light did not. Contrast between two gradients of the same resource produced a remarkable improvement in the predictive power of light over the performance of the studied species describing the small variations of light in forest understory.
\end{abstract}

Key words: disturbance, light contrast, shade tolerance, sunflecks, temporal elasticity.

Resumen: Las dificultades para medir a pequeña escala la heterogeneidad de luz en el sotobosque se refleja en la clasificación de especies, convencionalmente basada en su respuesta al claro o a la sombra, condiciones rara vez uniformes en el espacio y el tiempo. La heterogeneidad espacial y temporal expresada por el contraste entre la luz directa sobre un área (luz vertical) y la luz sobre sus alrededores, permitirá mejorar la estimación del ambiente de luz del sotobosque y de la respuesta de las especies a sus variaciones. Analizamos con medidas repetidas el efecto de luz vertical, contraste y distancia al claro sobre el desempeño de plántulas trasplantadas de Alnus acuminata, Cornus excelsa, Liquidambar styraciflua, Quercus laurina y Persea americana. Los Altos de Chiapas entre 1999 y 2005, en ocho parcelas de bosque de pino-encino, cada una con un claro central pequeño. Evaluamos la iluminación mediante fotografías hemisféricas al principio y al final del estudio. Se midió esbeltez y supervivencia a uno, dos, cuatro y seis años del trasplante. Distancia afectó la supervivencia de Alnus y Liquidambar. Luz vertical explicó esbeltez de Liquidambar. Contraste explicó esbeltez de Liquidambar, Cornus y Quercus y supervivencia de Liquidambar, Quercus y Persea, condicionada a la edad de la planta. La condición inicial de contraste inicial predijo la final, no así la luz vertical. El contraste entre dos gradientes del mismo recurso aumentó notablemente su poder predictivo sobre el desempeño de las especies al describir las pequeñas variaciones de luz en el sotobosque.

Palabras clave: contraste de luz, disturbio, sunflecks, elasticidad temporal, tolerancia a la sombra.

$S_{\text {pans }}^{\text {p }}$ patial heterogeneity is an ever-present characteristic of ecosystems. In the forest understory light intensity and direction varies constantly depending on openings in the canopy and on the angle of incidence at different time, season, latitude, and slope aspect (Hutchison and Matt, 1977).
Gap formation is a major source of local heterogeneity in forests involving, among other things, light, creating contrasting conditions within and around the gap where the forest physical structure acts as a light filter. The resulting sunflecks as well as their complementary shadeflecks vary 
in size, duration and intensity according to different temporal and spatial scales, and represent local light variation that may influence the growth of the herbaceous layer, young trees, and seedling abundance (Denslow, 1987; Chazdon, 1988; Smith et al., 1989; Canham, 1989; Way and Percy, 2012; Smith and Berry, 2013).

Measuring heterogeneity of light availability in forest understory remains as a challenging task. Although there is extensive literature on gap dynamics and sunflecks it is often hard for managers to interpret results due to inconsistent variability in methods which still are to a large extent arbitrary (Schliemann and Bockheim, 2011; Way and Pearcy, 2012). These difficulties are implicit in forest dynamic models that do not take small-scale variations into account (Deutschman et al., 1999; Baraloto and Couteron, 2010) inducing a kind of Simpson's paradox leading to a potentially important misleading interpretations of plant-environment interactions under dynamic irradiance regimes (Leakey et al., 2005) and hindering the understanding of the effects of heterogeneous light availability on plant performance. Plant individuals should exhibit phenotypic plasticity that allows them to cope with environmental heterogeneity which may directly affect the persistence of their populations facing long term changes (Gianoli, 2004; Nicotra, et al., 2010). Depending on how much of a specialist or a generalist the organism may be (Kolasa and Rollo, 1991) this responsiveness to changes in light intensity could be driven by relative tradeoffs between water loss and carbon absorption (Knapp and Smith, 1990; Naumburg and Ellsworth, 2000). These tradeoffs that might affect different performance parameters (e.g. growth pattern and eventually survival). For intolerant species survival the escape strategies include the production of tall and slender stems, with a minimum investment in diameter growth and leaves (Kohyama and Hotta, 1990; Gilbert et al., 2001; Coutand et al., 2010). Plant ability to tolerate shade in the forest understory depends on its efficient use of limiting resources as light, soil nutrients and water (Coomes and Grubb, 2000; Nilsen et al., 2009). This partitioning of resources for plants might vary not only along microhabitat gradients (Tilman, 1990; Suding and Goldberg, 2001) but also through their ontogeny (Coleman et al., 1994; Parrish and Bazzaz, 1985; Coomes and Grubb, 2000; Sultan, 2000; Wright and McConnaughay, 2002; Lusk, 2004). However it remains unclear to what extent the transient nature of sunflecks and shadeflecks in the understory may affect plant survival and growth (Naumburg and Ellsworth, 2000; Leakey et al., 2005). In addition, the time lags between changes in the light environment and plant responses further thwarts attempts to understand the effect of light on plant responses (Smith et al., 1992). The underlying mechanisms supporting functional classifications of plant response to light remain both scarce and controversial (Poorter and Garnier, 2007). This is partly because plant responses to light has been mainly studied only for short periods at early stages of plant development in the field (Ishida and Peters, 1999), and partly because plant responses to light variation has been mostly studied under controlled conditions in the laboratory (e.g. Sims and Pearcy, 1993; Watling et al., 1997; Huante et al., 1998; Stevens and Carson, 2002; Bloor and Grubb, 2004) with coarse grain excluding settings (light $v s$. shade) or in field gap vs. understory conditions, as if they were the more common conditions spatially and temporally speaking. Successional and seasonal variation, plus the complex effects of tree falls on the light environment show that a dichotomy between gap and understory or likewise between sun and shade, may be too simplistic for many purposes (Smith et al., 1992). Recent studies have demonstrated that the homogeneity in both gaps and understory conditions is the less frequent condition (Méndez-Dewar et al., 2014).

In this paper, we evaluate six years of plant response to the light heterogeneity under field conditions. We followed the framework proposed in Méndez-Dewar et al. (2014) which is a bidimensional scheme developed to describe plot heterogeneity to a fine scale by placing vertical light on growth area (Vertical light) as the y-axis, and the background light (Sidelight) in the horizontal axes. In such light map many understory conditions may be pinpointed with far more precision than the one-dimensional approaches may so far. Those authors have shown that this representation, estimated with measurements made at one point in time, allowed to accurately describe relationships between light spatial heterogeneity and seedling performance. In this contribution we test the time frame elasticity of such contrasts. We hypothesize that besides of the balancing effects of contrasting patches which may increase the performance of seedlings under homogeneously high or low light conditions, the span of such effects will be longer than the effects between Vertical light conditions and plant performance. We take that spatial and temporal variation of light may influence differentially plant performance depending on the initial light heterogeneity and on the shade-tolerance of each species. To this aim we studied the spatial and temporal light patch structure as a factor influencing interspecific differences in plant performance (stem slenderness and survival) in a number of field plots where gaps had been recently created and later regenerated naturally during six years of forest succession. For this study we evaluated transplanted seedlings growth of five native tree species (Alnus acuminata, Cornus excelsa, Liquidambar styraciflua, Persea americana, and Quercus laurina) over a period of six years in the field as a function of three gradients: distance to the center of the gap, direct light at growth area, and contrast between light at growth area with its neighboring area along the first six years of secondary succession following small gap phase regeneration in montane cloud forests of Chiapas, Mexico. These species differ in their shade-tolerance as judge by expert opinions. Hence, they offer a range of plant responses to 
explore a number of light heterogeneity metrics (RamírezMarcial et al., 2008).

\section{Materials and methods}

The study area, species, experimental designs, light measurements, light environment heterogeneity as well as the measurements on seedling performance are described briefly below, but a more detailed description can be found in Méndez-Dewar et al. (2014).

Study site. We conducted the study at Rancho Merced-Bazom, in the central highlands of Chiapas, Mexico $(2,300$ $\left.2,450 \mathrm{~m}, 16^{\circ} 44^{\prime} \mathrm{N}, 92^{\circ} 29^{\prime} \mathrm{W}\right)$. We collected field data in eight pine-oak forest plots each corresponding to a small, recent, naturally created gap ( $<2$ years old; E-W diameter, d $=7.5-15.0 \mathrm{~m}$, Table 1). Plots were protected against grazing and trampling. In each plot, we established N-S transects 3 $\mathrm{m}$ apart and points every $2.5 \mathrm{~m}$ along each transect (E-W).

Transplanted species and plant performance measurements. In March 1999, we transplanted one-year old seedlings produced in a nursery of Alnus acuminata Kunth $(\mathrm{N}=92)$, Liquidambar styraciflua $\mathrm{L}$. $(\mathrm{N}=124)$, Cornus excelsa Kunth (N =124), Quercus laurina Bonpl. $(\mathrm{N}=131)$, and Persea americana Mill. ( $\mathrm{N}=125)$ (from now onwards Alnus, Liquidambar, Cornus, Quercus, or Persea). We defined the spot or microsite where each transplanted seedling grows as the "growth area" $(G A)$ obtaining a total of 596 growth areas. We evaluated stem height $(S H, \mathrm{~cm})$ and basal stem diameter $(B S D, \mathrm{~mm} \times 10)$ within two, four and six years after transplantation. They were combined in an allometric shape ratio aimed to describe stem slenderness (Slenderness): This variable is unitless $(\mathrm{cm} / \mathrm{cm})$ and were used to assess plant performance.

$$
\text { Slenderness }=S H \times B S D^{-1}
$$

Light environment. In year 2005 we shot a series of 982 hemispheric photographs that followed the design of a similar sampling made in 1999 when the plots were initially stablished and the seedlings planted in the understory (Méndez-Dewar et al., 2014). Both samples were taken between 0700 and 1100 hours, under cloud overcast sunshine light along five consecutive days. Pictures were taken at $1.2 \mathrm{~m}$, above ground and analysed with Hemiphot (version 5, ter Steege, 1994). For the second series we used a digital camera Nikon Coolpix 995 equipped with a fish-eye lens Nikon (Fc-E8). We estimated the Direct Site Factor (DSF) from each photograph. This DSF corresponds to the Vertical light source for the growth area where each seedling was planted for the experiment.

Spatial light heterogeneity. The spatial distribution of DSF was described with three heterogeneity components (Méndez-Dewar et al., 2014): (1) Vertical light, which represents the highest spatial resolution in this study $\left(7.5 \mathrm{~m}^{2}\right)$ and by definition is internally homogeneous; (2) sidelight, obtained by clustering and averaging eight immediately adjacent neighboring patches (total of $60 \mathrm{~m}^{2}$ ), and (3) Spatial light Contrast for each of the 596 growth areas or microsites with the following equation:

$$
\begin{aligned}
& \text { Contrast }=(\text { Vertical light }- \text { Sidelight }) \times(\text { Vertical light }+ \\
&\text { Sidelight })^{-1} \\
&(\text { eq.2) }
\end{aligned}
$$

Background light levels for each growth area were defined by three factors: (1) distance from a given $G A$ to the center of the gap. Three distance $(D)$ classes were defined: (i) if $D$ $\leq$ radius $(r)$ of the gap, then the growth area was considered to be within the gap; (ii) if $\mathrm{r}<D \leq 2 r$ then the $G A$ was taken as at the "edge" of the gap; finally, (iii) if $D>3 r$ then the $G A$ was recorded as located inside the forest understory. (2) Vertical light classified in three levels: low (Vertical light $<$ $15 \%$ ), medium (Vertical light $<25 \%$ ), and high (Vertical light $>25 \%)$. (3) Contrast: negative $\left(C^{-}\right.$has values between -1 and -0.05$)$, null ( $C^{=}$between -0.049 a 0.049$)$ and positive $\left(C^{+}\right.$between 0.05 and 1$)$.

Analysis. Seedling height and diameter were measured at the time of transplant (1999), and one, two, four, and six years later. Stem slenderness ratio of each species $(S S)$ was analyzed for all plants alive six years after transplantation, to determine the long-term effects (regarded as fixed effects) of the three distance to the center of the gap $(D)$ classes (Gap, Edge and Understory), of three Vertical light levels (low, medium and high), and of the three types of light Contrast $\left(C^{-}, C^{=}\right.$, $C^{+}$). Predictive power of initial $D S F$ over what was measured six years later was compared with what happened with the light contrast using a linear regression. Stem slenderness was analyzed using a repeated measures two-way ANOVA along years $(Y)$ and final $D S F(2005)$ as random effects, allowing for the particular successional development effects at each growth area. The significance of differences in stem allometry was assessed with Tukey's posterior test. We contrasted two ANOVA models, with the initial heterogeneity components Vertical light and Contrast as factors not in the same model as they represent two light heterogeneity gradients (one-dimensional and bi-dimensional, respectively) whose temporal elasticity we intend to analyze separately. Plant survival was analyzed for each species with binary logistic regression (backwards procedure) as a function of $D, S S_{\mathrm{t}-1} ; V L$, and $C$. The $S S$ ratio entered was that of the previous time to the one at which death was recorded. All statistical analyses were performed using IBM-SPSS version 19 (2010).

\section{Results}

Spatial and temporal light variation. The equality of Vertical light and Sidelight corresponds to a "null contrast" or 

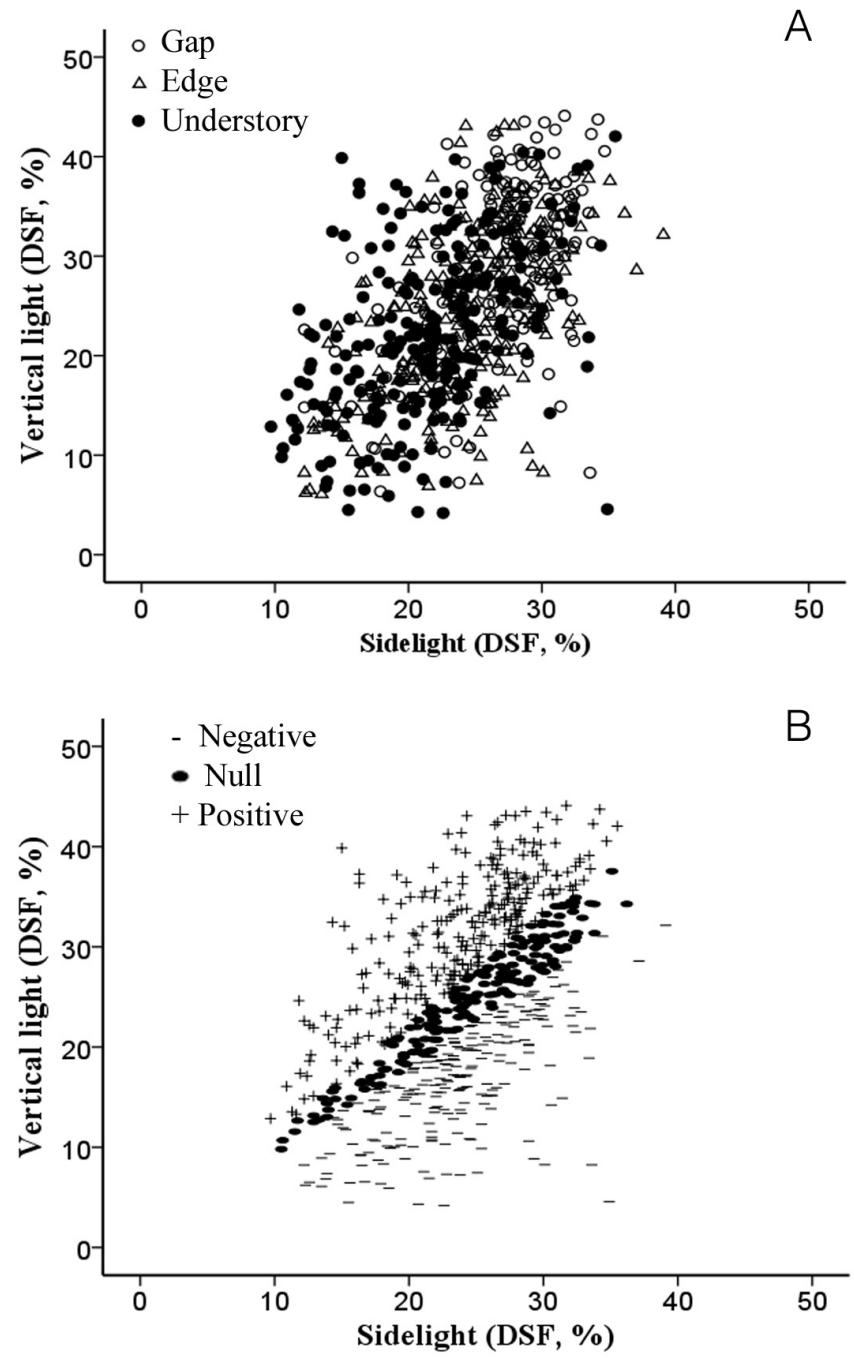

Figure 1. A) Fine grained heterogeneity observed in gaps (open circles), edge (triangles) and understory (solid circles) $(\mathrm{N}=680)$. B) Intersection of Vertical light and Sidelight values recorded in the forest understory and spatial light contrast of 680 points within eight plots with a small central gap. Positive contrasts $\left(\mathrm{C}^{+}\right)$: $\mathrm{VL}>$ SL; negative contrasts $\left(\mathrm{C}^{-}\right)$: $\mathrm{VL}<\mathrm{SL}$; null contrasts $\left(\mathrm{C}^{-}\right)$.

homogeneity and is represented in figure 1A by the identity line of these variables. At the spatial scale of this study, none of the three habitat types (Gap, Edge, or Understory) could

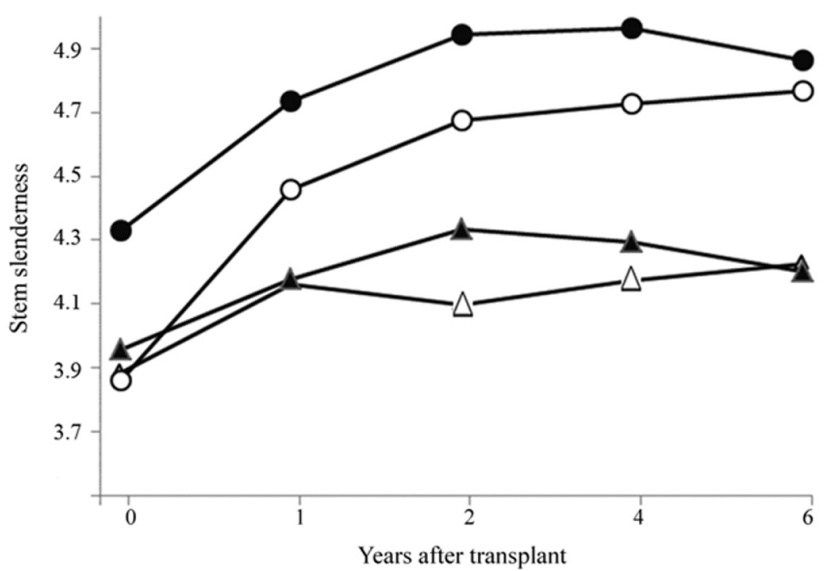

Figure 2. Change in stem slenderness ratio $(\mathrm{cm} / \mathrm{cm})$ of seedlings of four native tree species observed at different times along a six-year period after transplant into the understory of cloud forests in Chiapas, Mexico. Liquidambar (open circles), Cornus (solid circles),

Quercus (solid triangles) and Persea (open triangles).

be described either by Vertical light, Sidelight, or Contrast alone (Figure 1B). The level of light reaching the understory as expected was much reduced after six years of forest succession (Table 1). Vertical light did not predicted the final amount of light in the same point $\left(F_{1,653}=0.845, P=0.358\right)$, but the relationship between light contrast was much stron$\operatorname{ger}\left(F_{1,653}=514.826, P<0.001, r^{2}=0.43\right)$.

Seedling performance along six years in forest understory. Stem slenderness $(S S)$ was different among species since the beginning of the study $\left(F_{3,261}=93.81 ; P<0.0001\right.$; Figure 2 ). The maximum observed value of SS ratio was attained at different times. The most shade-intolerant species (Liquidambar) and Quercus attained relatively taller stems before Cornus or Quercus. Only Cornus shifted from low to high $S S$ ratio from one year after transplantation onwards, and Persea showed a relatively consistent height/diameter ratios through time (Figure 2). Data on Alnus were not included in this analysis because of the small number of plants surviving until the end of the study.

Vertical light values in growth area did not explain stem slenderness ratio changes along time for any species but

Table 1. Size of forest gaps $\left(\mathrm{m}^{2}\right)$, total plot size $\left(\mathrm{m}^{2}\right)$, initial (1999) and final (2005) mean direct site factor (DSF \pm SE) in each plot. DSF values with the same letter are not different with $P<0.05$. Frequency of negative, null and positive contrasts by plot $\left(C^{-}, C^{=}\right.$y $C^{+}$respectively).

\begin{tabular}{|c|c|c|c|c|c|c|c|c|}
\hline & $\begin{array}{l}\text { Plot } \\
1\end{array}$ & 2 & 3 & 4 & 5 & 6 & 7 & 8 \\
\hline Gap area $\left(\mathrm{m}^{2}\right)$ & 89.5 & 63.8 & 174 & 78.3 & 168 & 67.5 & 63 & 72 \\
\hline Plot area $\left(\mathrm{m}^{2}\right)$ & 682.5 & 450 & 945 & 577 & 892.5 & 472.5 & 577.5 & 375 \\
\hline$D S F_{\text {initial }}(\%)$ & $20.9\left(0.67^{b}\right.$ & $17.7\left(0.86^{\mathrm{a}}\right.$ & $21.7\left(0.81^{\mathrm{b}}\right.$ & $23.7\left(1.05^{b}\right.$ & $25.8\left(0.63^{c}\right.$ & $22.7\left(0.62^{\mathrm{b}}\right.$ & $27.1\left(0.59^{c}\right.$ & $26.0\left(0.89^{c}\right.$ \\
\hline $\begin{array}{l}D S F_{\text {final }}(\%) \\
\text { Contrast }\end{array}$ & $18.02\left(0.21^{b, c}\right.$ & $17.02\left(0.28^{a, b}\right.$ & $18.64\left(0.18^{\mathrm{c}}\right.$ & $17.01\left(0.20^{a, b}\right.$ & $16.61\left(0.30^{b, c}\right.$ & $15.49\left(0.21^{\mathrm{a}}\right.$ & $15.49\left(0.21^{\mathrm{a}}\right.$ & $16.22\left(0.29^{\mathrm{a}}\right.$ \\
\hline$\left(\mathrm{C}^{-}, \mathrm{C}^{=}, \mathrm{C}^{+}\right)$ & $34,33,37$ & $22,13,35$ & $49,25,52$ & $24,14,39$ & $47,40,32$ & $26,21,16$ & $17,28,30$ & $12,12,26$ \\
\hline
\end{tabular}



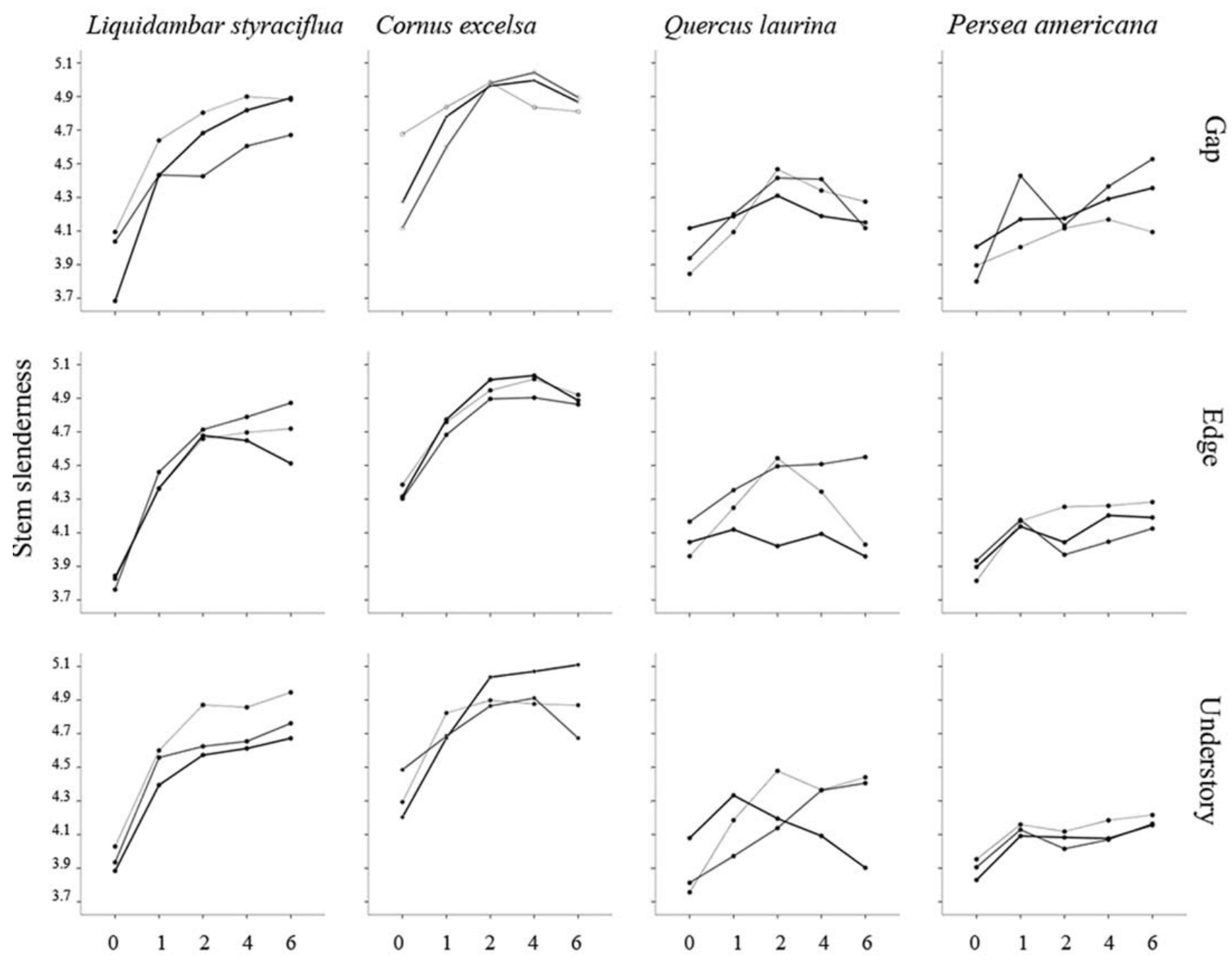

\section{Years after trasplant}

Figure 3. Changes in stem slenderness (height/basal diameter) of four native tree species arranged from left to right according to their increased shade tolerance, along a six-year period after their transplant into three habitat conditions (Gap, Edge, and Understory) in cloud forests in Chiapas, Mexico. Spatial light contrast is indicated by the thickness of the line: negative (thin), null (medium), and positive (thick).

Liquidambar, whose stem allometry was related to Vertical light (between subjects $F_{2,77}=4.495 ; P=0.014$ ). On the other hand, Contrast as a within subject effect, was found to be significant in all species in this study. Contrast was also the only factor with significant effects in interaction with Year $(Y)$ for Cornus and Quercus $\left(F_{2.94}=3.91 ; P=0.024\right.$ and $F_{2.94}=3.48 ; P=0.040$ ), and with both $Y$ and Distance in the shade-intolerant species (Cornus: $F_{4.94}=4.09 ; P=0.004$; Liquidambar: $F_{4,77}=2.67 ; P=0.038$ ) (Figure 3). Changes in $S S$ ratio of shade-intolerant species in the Gap and Edge habitat types were relatively similar (Figure 3), and it was in the understory habitat type where the response to either positive or negative contrasts became more evident. The effect of heterogeneity on Liquidambar, expressed as spatial light contrasts, was invariant through time. This could be explained by the between subjects effect of Contrast, independently of development stage $\left(F_{1,77}=5.47 ; P=0.006\right)$. Liquidambar developed more slender stems in Understory habitat with $C^{-}$. Growth curves of Quercus (a shade-tolerant species) show an antagonistic effect between $C^{=}$and $C^{+}$on $S S$ ratio both in the Edge and Understory habitat types.

Seedling mortality in heterogeneous understory. A total of 280 individuals died six years after transplantation (44\%). Survival was highest for Cornus (80 \%), Persea $(70 \%)$ and Liquidambar (68\%), and lowest for Quercus (38\%) and Alnus (12\%, Figure 4). Survival differences between species was significant since the first evaluation, and kept increasing afterwards (Wilcoxon statistic $>12.79 ; \mathrm{df}=4 ; P \leq$ 0.012 ). The effect of previous $S S$ ratio on plant survival was 
Table 2. Backward logistic regression of seedling survival at two, four and six years after transplant in forest understory as a function of Distance (D) to the center of the gap $(\mathrm{m})$, stem slenderness ratio at previous evaluation $\left(\mathrm{SS}_{\mathrm{t}-\mathrm{1}}\right)$, Vertical light $(\mathrm{VL})$, and spatial light Contrast at growth area (C). The table shows the estimated model parameter (B), its standard error (SE) and the significance $(P)$ of Wald's test. The estimate of the model fit is based on Nagelkerke's R² (Norušis, 1997).

\begin{tabular}{|c|c|c|c|c|c|c|c|c|c|}
\hline Species & Years & Independent & B & SE & Wald & $d f$ & $P$ & $\operatorname{Exp}(B)$ & $R^{2}$ \\
\hline \multirow[t]{2}{*}{ Alnus } & 2 & $\mathrm{D}$ & -0.12 & 0.06 & 3.70 & 1 & 0.054 & 0.89 & 0.07 \\
\hline & 4 & $\mathrm{D} \times \mathrm{VL}$ & -0.01 & 0.00 & 6.98 & 1 & 0.008 & 0.99 & 0.20 \\
\hline \multirow[t]{6}{*}{ Liquidambar } & 1 & C & 4.00 & 1.75 & 5.22 & 1 & 0.022 & 54.61 & 0.11 \\
\hline & 2 & $\mathrm{SS}_{\mathrm{t}-1}$ & 2.04 & 0.76 & 7.17 & 1 & 0.007 & 7.66 & 0.10 \\
\hline & 4 & $\mathrm{D} \times \mathrm{C}$ & 0.33 & 0.14 & 5.29 & 1 & 0.021 & 1.40 & 0.16 \\
\hline & & $\mathrm{SS}_{\mathrm{t}-1}$ & 1.69 & 0.83 & 4.20 & 1 & 0.040 & 5.43 & \\
\hline & 6 & $\mathrm{D}$ & -0.12 & 0.06 & 3.98 & 1 & 0.046 & 0.89 & 0.13 \\
\hline & & $\mathrm{D} \times \mathrm{C}$ & 0.27 & 0.13 & 3.93 & 1 & 0.047 & 1.31 & \\
\hline \multirow[t]{2}{*}{ Cornus } & 2 & $\mathrm{SS}_{\mathrm{t}-1}$ & 2.99 & 1.15 & 6.80 & 1 & 0.009 & 19.89 & 0.19 \\
\hline & 4 & $\mathrm{D}$ & -0.18 & 0.08 & 5.82 & 1 & 0.016 & 0.83 & 0.11 \\
\hline \multirow[t]{7}{*}{ Quercus } & 1 & $\mathrm{D} \times \mathrm{VL}$ & -0.01 & 0.00 & 4.56 & 1 & 0.033 & 0.99 & 0.11 \\
\hline & 2 & $\mathrm{D} \times \mathrm{C}$ & 0.40 & 0.17 & 5.75 & 1 & 0.017 & 1.49 & 0.08 \\
\hline & 4 & $\mathrm{SS}_{\mathrm{t}-1}$ & 1.12 & 0.56 & 3.98 & 1 & 0.046 & 3.06 & 0.05 \\
\hline & 6 & $\mathrm{D} \times \mathrm{VL}$ & -0.04 & 0.02 & 8.27 & 1 & 0.004 & 0.96 & 0.64 \\
\hline & & C & -50.78 & 19.71 & 6.64 & 1 & 0.010 & 0.00 & \\
\hline & & VL & 0.28 & 0.11 & 6.11 & 1 & 0.013 & 1.32 & \\
\hline & & $\mathrm{D} \times \mathrm{C}$ & 7.91 & 3.03 & 6.81 & 1 & 0.009 & $2,717.43$ & \\
\hline \multirow[t]{2}{*}{ Persea } & 4 & $\mathrm{SS}_{\mathrm{t}-1}$ & 3.45 & 1.07 & 10.40 & 1 & 0.001 & 31.59 & 0.18 \\
\hline & & C & 2.82 & 1.44 & 3.84 & 1 & 0.05 & 16.77 & \\
\hline
\end{tabular}

positive and significant for all species (but Alnus) with different times along their ontogeny: earlier for Liquidambar and Cornus $(P=0.007$ and $P=0.009$, respectively), than for Quercus and Persea $(P=0.046$ and $P=0.001$, respectively; Table 2). Distance to the center of the gap enhanced the probability of death of all species (but Persea): Quercus responded to Distance in every survival evaluation, Alnus responded to Distance two and four years after transplant $(P=0.054)$, and Cornus only four years after transplant $(P$

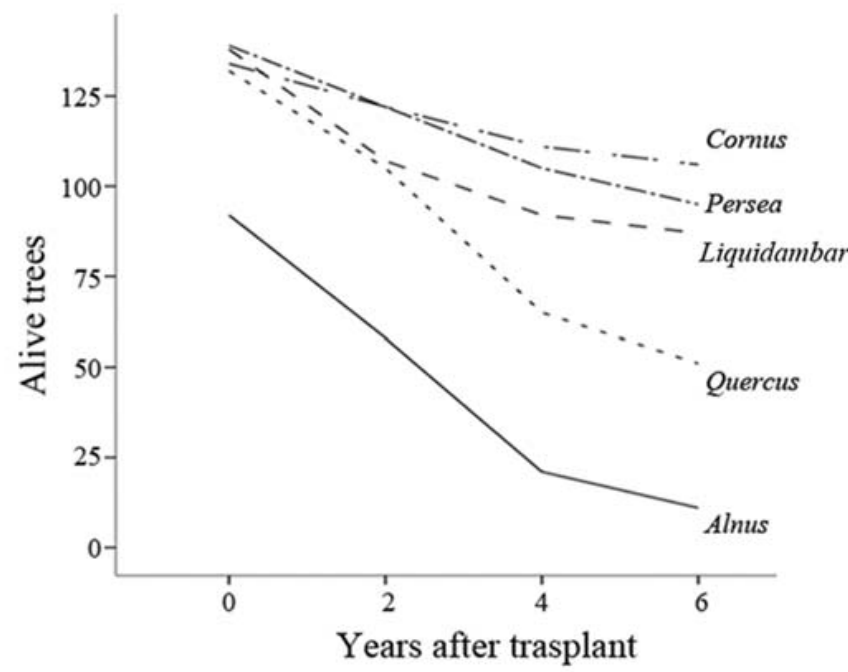

Figure 4. Mortality of one-year seedlings of five native tree species along a period of six years after being transplanted into cloud forests in Chiapas, México.
$=0.016)$ and Liquidambar only after six years $(P=0.046)$. Light contrast enhanced the probability of survival of Liquidambar one year after transplant $(P=0.022)$, as it did for Persea and Quercus four and six years after transplant, respectively $(P=0.050$ and $P=0.010$, respectively). A significant effect of Vertical light on survival of Quercus was also detected when the whole observation time was considered $(P=0.013)$.

The interaction between Distance and Contrast had a significant effect on survival of Liquidambar at four and six years after the transplant into the forest $(P=0.021$ and $P=0.047$, respectively). This interaction was also significant to explain the survival of Quercus at two and six years after the transplant $(P=0.017$ and $P=0.009$, respectively). The interaction between Distance and Vertical light was significant in Alnus four years after transplant (Wald statistic $=6.98 ; P=0.008$ ) and one and six years after Quercus $(P=0.033$ and $P=0.004$, respectively; Table 2). A higher mortality of Liquidambar and Quercus was observed with the intensifying effect of $C^{-}$and the Understory habitat type (Figure 5).

\section{Discussion}

In order to improve current understanding of plant-environment interactions under dynamic irradiance regimes typically found in field conditions, sunfleck assessment should recognize the importance of then levels context light (Lieffers et al., 1999; Leakey et al., 2005). Our results, obtained 
B Liquidambar styraciflua $(N=138)$
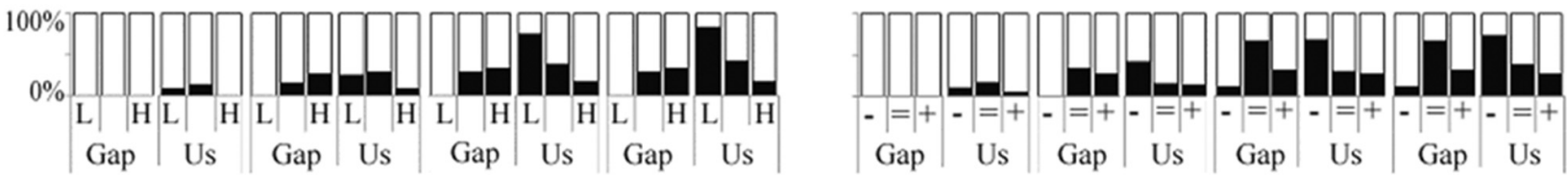

Cornus excelsa $\quad(N=134)$
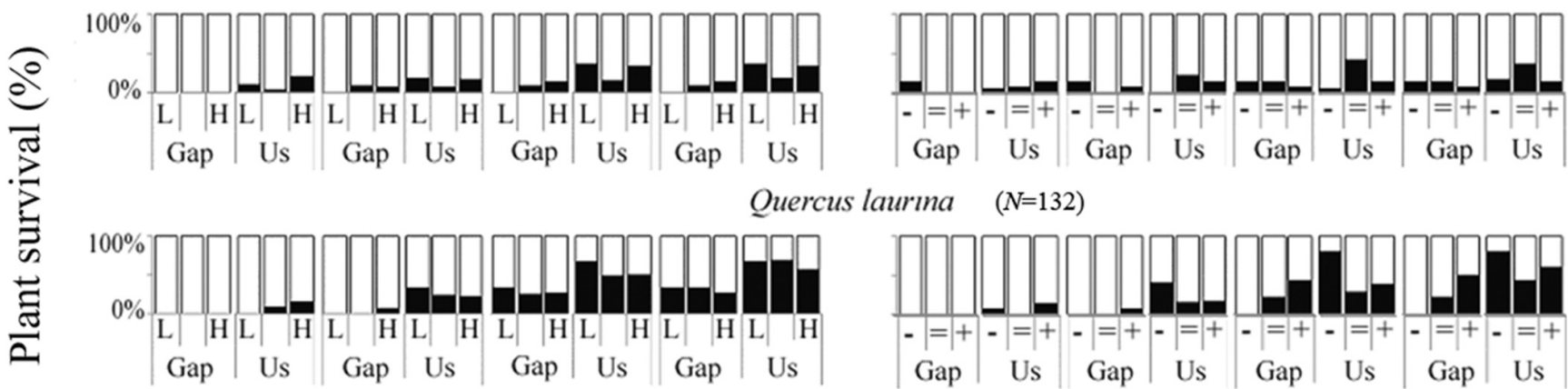

Quercus laurina $\quad(N=132)$

Persea americana $(N=139)$

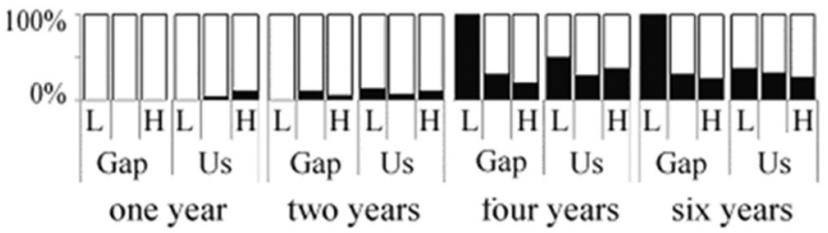

after trasplant
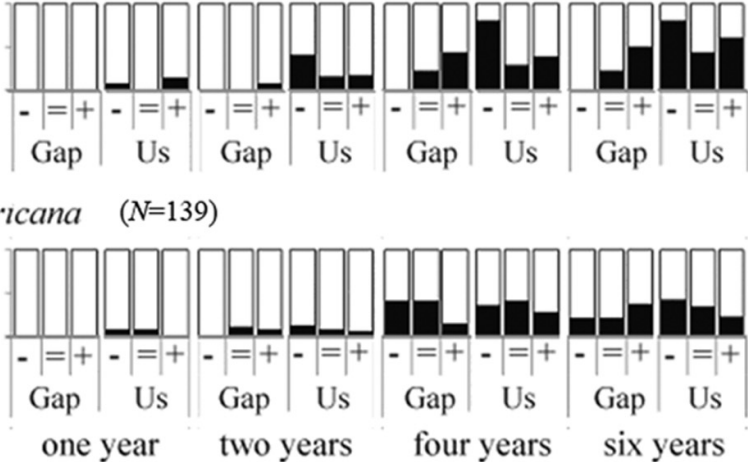

after trasplant

Figure 5. Relative survival of four native tree species a long a period of six years in two contrasting habitat conditions, Gap and Understory (Us), in cloud forests in Chiapas, Mexico. Proportion of dead individuals is shown in black. A) Response to three light levels: Low (L), Medium (M), and High (H). The letter M is not shown between L and $\mathrm{H}$ because of space restrictions. B) Response to three different types of spatial light contrast: negative $(-)$, null $\left(^{(}\right)$and positive $\left(^{+}\right)$.

under field conditions, provide evidence that thresholds for sunflecks should be related to the light demands of the understory species either within a habitat mosaic or along a successional path.

Light heterogeneity and successional changes in montane forests. At the spatial scale of this study none of the three habitat types (Gap, Edge, or Understory) could be explained by Vertical light, Sidelight, or Contrast alone, suggesting the existence of a potential large number of fine-scale microhabitats variables in moderately disturbed forests. During secondary succession, as a stand undergoes crown closure, light transmission to the understory may decline sharply (Horn, 1971; Kane et al., 2011). Light intensity, as experienced by the plants at the beginning of the study, were not correlated with that prevailing after six years. The information used to determine the light contrast allows for a reconstruction of the microenvironment along a hypothetical successional routes, with more predictive power. The light contrasts consider a number of structural attributes at the canopy and understory levels (e.g. stem density, basal area) that collectively determine the forest light filter (Méndez-
Dewar et al., 2014). In this regard, we consider that after six years microsites initially classified as $C^{+}$, for example, will share more coincidences among themselves. In them it was more likely that the cover of plants located in neighboring shaded points would continue over the illuminated area. A less likely process is one where the vegetation of the neighboring area could lose cover.

Seedling responses to light heterogeneity in montane forests. In our six year study we found evidence supporting the idea that microenvironmental heterogeneity, evaluated with light contrasts, influenced SS seedling survival. In consistency with findings on resource allocation (Canham, 1989; Bloor and Grubb, 2004; Coutand et al., 2010), shade-intolerant species developed longer and slender stems than the shadetolerant ones. The curves of SS ratio changes of shade-intolerant species through time are parallel in the Gap and Edge habitat types, but not in the Understory habitat, as shade-intolerant traits show the most plastic responses to an increase in light at the lower end of the gradient (e.g. Veenendaal et al., 1996; Poorter, 1998). However, the shade-tolerant Persea showed more similar responses in the Understory than in 
the Gap or Edge habitat types. It has been suggested that the phenotypic plasticity could induce greater competitive capacity under irregularly changing environments (Givinish, 2002). There is mounting evidence suggesting that plants have epigenetic mechanisms in their cells that provide them with the capacity to memorize a history of exposition to stressors and specifically to "sun footprints" in terms of UV and light stress (Müller-Xing et al., 2014). Notwithstanding that we did not find a significant effect of Vertical light on the performance of all species we studied (but Liquidambar), its effect is clearly implicit and better described in our light contrasts, as we observed intraspecific differences in the norm of reaction under different types of contrast. Survival was affected by distance to the center of the gap and was higher in the Gap than in the Understory habitat type (with the exception of the shade-tolerant Persea).

Light heterogeneity: intensifying vs. balancing effects. The ecological interpretation of the light contrasts is focused on the supplement effects (Parish and Bazzaz, 1985; Stuefer et al., 1994; Stuefer, 1996; Hutchings and Wijesinghe, 1997) suggesting that increase survival depends on the habitat context: a $C^{-}$may have a soothing effect in gaps and hardens conditions within a shade continuum in the understory. On the contrary, a $C^{+}$may have an intensifying effect in the gap and a balancing one in the understory (Méndez-Dewar $e t$ al., 2014). In a Gap open habitat $C^{-}$may have complementary effects on Liquidambar and Quercus as they had lower mortality under those conditions and responded to surrounding shade with longer and slender stems, which may help to avoid or at least reduce competitive suppression (Smith, 1982; Holbrook and Putz, 1989; Schwinning and Weiner, 1998). On the other hand, in Gap habitat the light intensifying effects $\left(C^{+}, C^{=}\right)$, reduced Liquidambar survival. This results striking cause Liquidambar is regarded as a typical heliophile shade-intolerant species (Herrick and Thomas, 1999). Some species cannot fully use periods of extremely bright light (Sims and Pearcy, 1993), because of low relative humidity, and (or) high leaf temperature load or UV damaging exposition as likely mechanisms underlying this reaction (Weis and Berry, 1988; Niinemets, 1998; McDonald and Urban, 2004; Brenes-Arguedas et al., 2011), or photoinhibition (Powles, 1984; Kitao et al., 2006). This suggest that analysis of its performance in Gap habitat as a function of some of the proposed light heterogeneity metrics allows us to gain insight into its more complex responses to spatially and temporally varying environments. In Understory habitat, increasing $D S F$ values in $C^{+}$produced stem elongation of Cornus. Under these relatively shaded conditions, high light availability is relatively small (only when the sun is close to the zenith) and possibly limiting. Therefore, only species with a highly responsive photosynthetic machinery would benefit from the balancing effects of a $C^{+}$as intermittent intense light flashes the spot (Pearcy et al., 1994).
On the other hand, the effect of shade intensification in the Understory habitat type may reduce net carbon gain and plant growth (Katahata et al., 2005). The results showed a negative effect of $C^{-}$where stem height of Liquidambar was lowest (even with high $S S$ ratio), and the largest number of dead plants of this species was recorded. Although a higher survival was expected in shade-tolerant species in the Understory habitat type, the survival of Liquidambar and Cornus was higher than it was in the shade-tolerant Quercus.

Ontogeny in heterogeneous understory. This study presents an approach to quantify, at the stand level, the idea of balancing patches that represent likely temporal and spatial shifts in the complementarity of positive and negative effects of microsites. Spatial heterogeneity may affect performance at any age of the plant, but as we observed in Liquidambar and Cornus, its consequences may be more severe in early stages of the life cycle (Strauss-Debenedetti and Bazzaz, 1991; Gómez, 2003). Shade-tolerant species responded to light heterogeneity at all evaluated conditions, which is consistent with previous studies (e.g. Pearcy, 1987; Rozendaal et al., 2006). This suggests that shade-tolerant climax species may exhibit a wider plasticity because of large ontogenetic latitude through their life cycle. The trade-off could be as extreme as not growing at all but surviving under low light and then grow quickly under high light conditions (Kitajima, 1994; Kitajima and Bolker, 2003). So, if homogeneity is the less frequent habitat condition in forest understory it could be expected that only a few species specialized in using homogeneous environments could be able to occupy any of the two extremes of the light gradient in our bi-dimensional plane and also that most plant species (including those followed in this study) might be subjected to selection on this bi-dimensional light intensity and heterogeneity gradient where subtle balancing effects are well depicted.

Different forest scenarios that could be useful to rank the shade-tolerance dichotomy can be envisaged within the light contrast framework. In this sense, we evaluate the responses of seedlings and saplings under a wider but also more precise range of light contrasts than are conventionally included in old-growth forests, when only gap or non-gap areas are visualized. This study provides spatially explicit information about six years of forest regeneration. We ascertain that, with this sample, the spatial light contrast clearly is a good sensor of stand development related to other attributes of forest structure. These structural attributes jointly determine the quantity and quality of light that filters down onto the forest floor, with effects that enhances availability of other resources at both above and below ground levels (Coomes and Grubb, 2000). We are convinced that spatial light contrasts are useful in developing more complex functional and successional schemes with adequate elasticity to span forest recovery needed in the development of improved functional 
FROM SEEDLING TO SAPLING: TREE SPECIES RESPONSES TO SPATIAL AND TEMPORAL UNDERSTORY LIGHT HETEROGENEITY

classification of forest species that could better support the management of highly species-rich forests.

\section{Acknowledgements}

We thank A. Luna-Gómez, M. Martínez-Icó, L. GascaSuárez, H. E.Castañeda-Ocaña, B.A. Pérez-Espinosa, and I. Romero-Nájera for their help during the fieldwork. We thank: Camacho-Cruz for providing seedlings. K. McMillan for comments and a revision of the English language and two anonymous reviewers. The Consejo Nacional de Ciencia y Tecnología (CONACYT) provided a scholarship to GMD (Ref. no. 124319). Research supported by the European Commission through the SUCRE Project (ERBIC-18TC 970146; INCO-DC Programme, Framework 4), the BIOCORES Project (ICA4-TC-2001-10095; INCO Programme, Framework 5), the FOREST Project (Alpha Programme of the European Comission, 2005-2007), and by Federal subsidies to MGE at ECOSUR (from 1997 onwards); and by ROBIN Project funded by the European Union's Seventh Framework Programme (THEME ENV.2011.2.1.4-1 - Potential of biodiversity and ecosystems for the mitigation of climate change). Grant agreement No: 283093. We are also grateful for the grant provided to the Instituto de Ecología, A.C. by the now Instituto Nacional de Ecología y Cambio Climático (INECC) through its Climate Change Program to the project "Análisis de efectos y costos del Cambio Climático en Servicios Ambientales de bosques y selvas, captación de agua y amortiguamiento de impacto de lluvias extremas".

\section{Literature cited}

Baraloto C. and Couteron P. 2010. Fine-scale microhabitat heterogeneity in a French Guiana forest. Biotropica 42:420-428.

Bloor J.M.G. and Grubb P.J. 2004. Morphological plasticity of shade-tolerant tropical rainforest tree seedlings exposed to light changes. Functional Ecology 18:337-348.

Brenes-Arguedas T., Roddy A.B., Coley P.D. and Kursar T.A. 2011. Do differences in understory light contribute to species distributions along a tropical rainfall gradient? Oecologia 166:443-456.

Canham C.D. 1989. Different responses to gaps among shade-tolerant tree species. Ecology 70:548-550.

Chazdon R.L. 1988. Sunflecks and their importance to forest understory plants. Advances in Ecological Research 18:1-63.

Chazdon R.L. and Pearcy R.W. 1986. Photosynthetic responses to light variation in rainforest species. I. Induction under constant and fluctuating light conditions. Oecologia 69:517-523.

Coleman J.C., McConnaughay K.D.M. and Ackerly D.D. 1994. Interpreting phenotypic variation in plants. Trends in Ecology and Evolution 9:187-191.

Coomes D.A. and Grubb P.J. 2000. Impacts of root competition in forests and woodlands: a theoretical framework and review of experiments. Ecological Monographs 70:171-207.

Coutand C., Chevolot M., Lacointe A., Rowe N. and Scotti I. 2010.
Mechanosensing of stem bending and its interspecific variability in five neotropical rainforest species. Annals of Botany 105:341-347.

Denslow J.S. 1987. Tropical rain forest gaps and tree species diversity. Annual Review of Ecology Evolution and Systematics 18:431-451.

Deutschman D.H., Levin S.A. and Pacala S.W. 1999. Error propagation in a forest succession model: the role of fine-scale heterogeneity in light. Ecology 80:1927-1943.

Gianoli E. 2004. Plasticity of traits and correlations in two populations of Convolvulus arvensis (Convolvulaceae) differing in environmental heterogeneity. International Journal of Plant Science 165:825-832.

Gilbert I.R., Jarvis P.G. and Smith H. 2001. Proximity signal and shade avoidance differences between early and late successional trees. Nature 411:792-795.

Gómez J.M. 2003. Spatial patterns in long-distance dispersal of Quercus ilex acorns by jays in a heterogeneous landscape. Ecography 26:573-584.

Givinish T.J. 2002. Ecological constraints on the evolution of plasticity in plants. Evolutionary Ecology 16:213-242.

Herrick J.D. and Thomas R.B. 1999. Effects of $\mathrm{CO}_{2}$ enrichment on the photosynthetic light response of sun and shade leaves of canopy sweetgum trees (Liquidambar styraciflua) in a forest ecosystem. Tree Physiology 19:779-786.

Holbrook N.M. and Putz F.E. 1989. Influence of neighbors on tree form: effects of lateral shade and prevention of sway on the allometry of Liquidambar styraciflua (sweet gum). American Journal of Botany 76:1740-1749.

Horn H.S. 1971. The Adaptive Geometry of Trees. Princeton University Press, Princeton.

Huante P., Rincón E. and Chapin F.S.III. 1998. Effect of changing light availability on nutrient foraging in tropical deciduous treeseedlings. Oikos 82:449-458.

Hutchings M.J. and Wijesinghe D.K. 1997. Patchy habitats, division of labour and growth dividends in clonal plants. Trends in Ecology and Evolution 12:390-394.

Hutchison B.A. and Matt D.R. 1977. The distribution of solar radiation within a deciduous forest. Ecological Monographs 47:185-207.

IBM. 2010. IBM-SPSS version 19.2010. Chicago.

Ishida M. and Peters R. 1999. Effects of potential PAR on shoot extension in juveniles of the main tree species in a Japanese temperate forest. Ecological Research 13:171-182.

Katahata S., Naramoto M., Kakubari Y. and Mukai Y. 2005. Photosynthetic acclimation to dynamic changes in environmental conditions associated with deciduous overstory phenology in Daphniphyllum humile, an evergreen understory shrub. Tree Physiology 25:437-445.

Kane V.R., Gersonde R.F., Lutz J.A., Mcgaughey R.J., Bakker J.D. and Franklin J.F. 2011. Patch dynamics and the development of structural and spatial heterogeneity in Pacific Northwest forests. Canadian Journal of Forest Research 41:2276-2291.

Kitajima K. 1994. Relative importance of photosynthetic traits and allocation patterns as correlates of seedling shade tolerance of 13 tropical trees. Oecologia 98:419-428.

Kitajima K. and Bolker M.B. 2003. Testing performance rank reversals among coexisting species: crossover point irradiance analysis. Functional Ecology 17:276-281.

Kitao M., Lei T.T., Koike T., Tobita H. and Maruyama Y. 2006. 
Tradeoff between shade adaptation and mitigation of photoinhibition in leaves of Quercus mongolica and Acer mono acclimated to deep shade. Tree Physiology 26:441-448.

Knapp A.K. and Smith W.K. 1990. Stomatal and photosynthetic responses to variable sunlight. Physiologia Plantarum 78:160165.

Kolasa J. and Rollo C. 1991. Introduction: the heterogeneity of heterogeneity: a glossary. In: Kolasa J. and Pickett S.T.A. Eds. Ecological heterogeneity, pp. 1-23, Springer-Verlag, New York.

Kohyama T. and Hotta M. 1990. Significance of allometry in tropical saplings. Functional Ecology 4:515-521.

Leakey A.D., Scholes J.D. and Press M.C. 2005. Physiological and ecological significance of sunflecks for dipterocarp seedlings. Journal of Experimental Botany 56:469-482.

Lieffers V.J., Messier C., Stadt K.J., Gendron F. and Comeau P.G. 1999. Predicting and managing light in the understory of boreal forests. Canadian Journal of Forest Research 29:796-811.

Lusk C.H. 2004. Leaf area and growth of juvenile temperate evergreens in low light: species of contrasting shade tolerance change rank during ontogeny. Functional Ecology 18:820-828.

McDonald R.I. and Urban D.L. 2004. Forest edges and tree growth rates in the North Carolina Piedmont. Ecology 85:2258-2266.

Méndez-Dewar G., González-Espinosa M. and Equihua M. 2014. Spatial heterogeneity of light and tree sapling responses in the understory of disturbed montane forests. iForest Biogeosciencs and Forestry 8:448-455.

Müller-Xing R., Xing Q., and Goodrich J. 2014. Footprints of the sun: memory of UV and light stress in plants. Frontiers in Plant Science 5:1-12.

Naumburg E. and Ellsworth D. 2000. Photosynthetic sunfleck utilization potential of understory saplings growing under elevated $\mathrm{CO}_{2}$ in FACE. Oecologia 122:163-174.

Nicotra A.B., Atkin O.K., Bonser S.P., Davidson A.M., Finnegan E.J., Mathesius U., Poot P., Purugganan M.D., Richards C.L., Valladares F. and van Kleunen. 2010. Plant phenotypic plasticity in a changing climate. Trends in Plant Science 15:684-692.

Niinemets Ü. 1998. Growth of young trees of Acer platanoides and Quercus robur along a gap-understory continuum: interrelationships between allometry, biomass partitioning, nitrogen, and shade-tolerance. International Journal of Plant Sciences 159:318-330.

Nilsen E.T., Lei T.T. and Semones S.W. 2009. Presence of understory shrubs constrains carbon gain in sunflecks by advance-regeneration seedlings: evidence from Quercus rubra seedlings growing in understory forest patches with or without evergreen shrubs present. International Journal of Plant Sciences 170:735-747.

Norušis, M.J. 1997. SPSS 7.5 Guide to Data analysis. Prentice Hall, Upper Saddle River, N.J., USA.

Parrish J.A.D. and Bazzaz F.A. 1985. Ontogenetic niche shifts in old-field annuals. Ecology 66:1296-1302.

Pearcy R.W. 1987. Photosynthetic gas exchange responses of Australian tropical forest trees in canopy, gap and understorey micro-environments. Functional Ecology 1:169-178.

Pearcy R.W., Chazdon R.L., Gross L.J. and Mott K.A. 1994. Photosynthetic utilization of sunflecks, a temporally patchy resource on a time scale of seconds to minutes. In: Caldwell M.M. and Pearcy R.W. Eds. Exploitation of Environmental Heterogeneity by Plants: Ecophysiological Processes above and below ground, pp. 175-208. Academic Press, San Diego.
Poorter L. 1998. Seedling growth of Bolivian rain forest tree species in relation to light and water availability. $\mathrm{Ph}$. D. Thesis. Utrecht University, Riberalta. 195 pp.

Poorter H. and Garnier E. 2007. Ecological significance of variation in relative growth rate and its components. In: Pugnaire F.I. and Valladares F. Eds. Functional Plant Ecology, pp. 67-100, CRC Press, Boca Raton.

Powles S.B. 1984. Photoinhibition of photosynthesis induced by visible light. Annual Review of Plant Physiology 35:15-44.

Ramírez-Marcial N., Camacho-Cruz A. and González-Espinosa M. 2008. Clasificación de grupos funcionales vegetales para la restauración del bosque mesófilo de montaña. In: Sánchez-Velásquez L.R., Galindo-González J. and Díaz-Fleischer F. Eds. Ecología, Manejo y Conservación de los Ecosistemas de Montaña en México, pp.51-72. Mundi-Prensa, México, D.F., México.

Rozendaal D.M.A., Hurtado V.H. and Poorter L. 2006. Plasticity in leaf traits of 38 tropical tree species in response to light; relationships with light demand and adult stature. Functional Ecology 20:207-216.

Schliemann S.A. and Bockheim J.G. 2011. Methods for studying treefall gaps: a review. Forest Ecology and Management 261:1143-1151.

Schwinning S. and Weiner J. 1998. Mechanisms determining the degree of size asymmetry in competition among plants. Oecologia 113:447-455.

Sims D.A. and Pearcy R.W. 1993. Sunfleck frequency and duration affects growth rate in understorey plant, Alocasia macrorrhiza. Functional Ecology 7:683-689.

Smith H. 1982. Light quality, photoreception, and plant strategy. Annual Review of Plant Physiology 33:481-518.

Smith W., Knapp A. and Reiners W. 1989. Penumbral effects on sunlight penetration in plant communities. Ecology 70:16031609.

Smith A., Hogan K. and Idol J. 1992. Spatial and temporal patterns of light and canopy structure in a lowland tropical moist forest. Biotropica 24:503-511.

Smith W.K. and Berry Z.C. 2013. Sunflecks? Tree Physiology 33:233-237.

Stevens M.H.H. and Carson W.P. 2002. Resource quantity, not resource heterogeneity, maintains plant diversity. Ecology Letters 5:420-426.

Strauss-Debenedetti S. and Bazzaz F.A. 1991. Plasticity and acclimation to light in tropical Moraceae of different successional positions. Oecologia 87:377-387.

Stuefer J.F. 1996. Potential and limitations of current concepts regarding the response of clonal plants to environmental heterogeneity. Vegetatio 127:55-70.

Stuefer J.F., During H. and de Kroon H. 1994. High benefits of clonal integration in stoloniferous species in response to heterogeneous light environments. Journal of Ecology 82:511-518.

Suding K.N. and Goldberg D. 2001. Do disturbances alter competitive hierarchies? Mechanisms of change following gap creation. Ecology 82:2133-2149.

Sultan S.E. 2000. Phenotypic plasticity for plant development, function and life history. Trends in Plant Science 5:537-542.

ter Steege H. 1994. Hemiphot: a programme to analyze vegetation indices, light and light quality from hemispherical photographs. Tropenbos, Wageningen, Netherlands.

Tilman D. 1990. Constraints and tradeoffs: toward a predictive theory of competition and succession. Oikos 58:3-15. 
FROM SEEDLING TO SAPLING: TREE SPECIES RESPONSES TO SPATIAL AND TEMPORAL UNDERSTORY LIGHT HETEROGENEITY

Veenendaal E.M., Swaine M.D., Agyeman V.K., Blay D., Abebrese I.K. and Mullins C.E. 1996. Differences in plant and soilwater relations in and around a forest in West Africa during the dry season may influence seedling establishment and survival. Journal of Ecology 84:83-90

Watling J.R., Ball M.C. and Woodrow I.E. 1997. The utilization of lightflecks for growth in four Australian rain-forest species. Functional Ecology 11:231-239.

Way D.A. and Pearcy R.W. 2012. Sunflecks in trees and forests:

Received: May 23rd, 2014

Accepted: November 7th, 2014 from photosynthetic physiology to global change biology. Tree Physiology 32:1066-1081.

Weis E. and Berry J.A. 1988. Plants and high temperature stress. Symposia of the Society for Experimental Biology 42:329346.

Wright S.D. and McConnaughay K.D.M. 2002. Interpreting phenotypic plasticity: the importance of ontogeny. Plant Species Biology 17:119-131. 